\title{
LA MEJOR VERSIÓN DE SÍ MISMOS. EDUCAR LA INDIVIDUALIDAD A PARTIR DE LA FILOSOFÍA DE NIETZSCHE
}

\author{
The best version of themselves. \\ Educating to individuality starting from Nietzsche's philosophy
}

\author{
Benedetta Zavatta
}

École normale supérieure de París

\begin{abstract}
Resumen: Este artículo ilustra el concepto de educación de Nietzsche tal como emerge en las Consideraciones intempestivas, se desarrolla en las obras del período medio (Aurora, Humano, demasiado humano I y II, La Gaya ciencia) y culmina en Así habló Zaratustra. También discute la crítica de Nietzsche a las instituciones educativas de su tiempo y la idea alternativa de educar con el ejemplo. Finalmente, la posibilidad y utilidad de utilizar algunas de las ideas de Nietzsche para la enseñanza contemporánea- especialmente el ideal de superación y superación personal -, se evaluará y discutirá críticamente con los estudiosos que han tratado este tema.

Palabras clave: Educación - educador - superhombre - auto-superación - autoperfeccionamiento - individualidad-democracia
\end{abstract}

ABSTRACT: This essay illustrates the Nietzschean concept of education as it emerges in the Untimely Considerations, is developed in the works of the middle period (Daybreak, Human, All Too Human I and II, The Gay Science) and culminates in Thus Spoke Zarathustra. It also discusses Nietzsche's critique of the educational institutions of his time and the alternative idea of educating by example. Finally, in this essay the possibility and usefulness of using some of Nietzsche's ideas for contemporary teaching - above all the ideal of self-overcoming and selfperfectioning - will be evaluated, and the different theories on this regard critically discussed.

Keywords: Education - educator - overman - self-overcoming - self-perfectionism individuality - democracy

ESTUDIOS NIETZSCHE, 21 (2021), pp. 127-150. ISSN: 1578-6676.

(c) Sociedad Española de Estudios sobre Friedrich Nietzsche (SEDEN)

Recibido: 30-09-2021 Aceptado: 23-09-2021

Esta obra está bajo licencia internacional Creative Commons Reconocimiento-NoComercial-Compartirlgual 4.0. 


\section{EDUCACIÓN COMO AUTODISCIPLINA}

En Ecce Homo Nietzsche nos revela que en el tercer y cuarta Consideraciones Intempestivas, las figuras de Schopenhauer y Wagner nos son más que un pretexto para comunicar sus ideas, exactamente como Platón ha puesto en boca de Sócrates su filosofía. Se trata por lo tanto de personajes fuertemente idealizados que del Schopenhauer y Wagner históricos conservan sólo las características útiles y vehiculares de aquello que Nietzsche quiere transmitir a sus lectores. Nietzsche también en Ecce Homo puntualiza que el tema de esos dos escritos afrontan «un problema de educación» (EH, Consideraciones 3) extremamente urgente e importante. La educación que Nietzsche tiene en mente consiste, nos dice en «un nuevo concepto de autodisciplina, de autodefensa» (EH Consideraciones 3). En las páginas siguientes nos proponemos aclarar en qué consiste tal nuevo concepto de educación al que Nietzsche alude y el modo en que ella puede ser impartida. A continuación, discutiremos sobre la posibilidad y utilidad de utilizar algunas ideas de Nietzsche para la didáctica contemporánea, confrontándolas con los estudiosos que se han expresado sobre este argumento.

\section{SER SÍ MISMO: ORIGINALIDAD FRENTE A CONFORMISMO}

La tercera Consideración intempestiva se abre con una denuncia del conformismo y mediocridad que caracterizan a la cultura moderna. Nietzsche atribuye la responsabilidad a la instrucción impartida en las instituciones educativas de su tiempo, las cuales son acusadas de limitar el potencial del individuo $\mathrm{y}$, por tanto, de la sociedad entera. Las corrientes prácticas pedagógicas están sometidas de hecho a otros objetivos y no a la verdadera formación del individuo. La lógica del mercado y de la producción prescribe procurar a los jóvenes el mayor número de conocimientos posibles, de manera que estos puedan trabajar enseguida y ganar lo más posible para satisfacer las falsas necesidades que la sociedad de consumo les ha inculcado. El objetivo es el de hacer a los individuos «corrientes», en la misma acepción en la que se define una moneda «corriente» (SE 6). Ellos deben de estar en condiciones de cambiar fácilmente su propio trabajo con bienes comerciales, de manera que constituyen un engranaje bien engrasado en el mecanismo del mercado. Cuanto mayor es la capacidad de ganar, tan mayor es el potencial de ser felices: este es el mensaje que se inculca a las generaciones jóvenes para motivarlas a estudiar. En la barbarie de la vida moderna están prohibidas todas las actividades que no tengan como objetivo inmediato ganar dinero, en la producción de mercancías, y que exijan tiempo. Expresando incluso un juicio moral sobre ellas, se las define «egoístas» porque no contribuirían al buen funcionamiento de la sociedad de consumo. El segundo promotor de 
la cultura, después del mercado, es el Estado. Pero también en este caso, la cultura que promueve es simplemente la instrucción necesaria para servir a las instituciones existentes. Por lo tanto, en lugar de liberar al individuo, también este tipo de pedagogía no hace otra cosa que encadenarlo más a la máquina del Estado. ${ }^{1}$ Finalmente, Nietzsche cita la deletérea moda de la «bella forma» (SE 6), por la que el hombre de cultura debe ser amanerado y capaz de presumir del propio nocionismo. Esta bella forma debe enmascarar la fealdad del hombre moderno, que se ha convertido en mezquino y codicioso, viciado y rebelde, incapaz de autocontrol, de disciplina y de los sacrificios que conducen a la nobleza y grandeza. Incluso la ciencia debe contarse entre las potencias que determinan las actuales prácticas pedagógicas. Ella exige seres humanos que sepan ser meticulosos y objetivos, es decir, que sepan concentrarse sobre lo particular olvidando la visión general y que sepan ocultar sus propias emociones a fin de que no intervengan en el proceso de producción del conocimiento. Este training, como Nietzsche ya denunciaba en la segunda Consideración intempestiva, conduce al debilitamiento de la personalidad del estudioso, que llega a ser incapaz de formular juicios en primera persona. Frente a la moderna pedagogía, sometida al Estado y al mercado, que dota al individuo de la instrucción necesaria para vivir de manera parecida a los animales, Nietzsche reivindica la necesidad de un nuevo tipo de educación. Él invoca una pedagogía que favorezca el reforzamiento de la personalidad individual, la expresión libre y orignal de sí y la emergencia en cada uno del propio talento peculiar. Nietzsche introduce estos conceptos indirectamente, a través de la figura heroica e intempestiva de Schopenhauer. Intempestiva, porque la filosofía de Schopenhauer se opone fuertemente a los ideales de la época. Heroica porque éste ha sabido estoicamente soportar la culpa y el aislamiento a los que la sociedad de masas, por definición, condena a todo pensador original. A través del retrato de Schopenhauer y del modo en que lo vivió Nietzsche quiere contrastar el ideal de una pequeña felicidad, derivada del disfrute de los bienes materiales y de la aceptación por parte de las masas, con el ideal de una vida heroica, empleada para expresar el propio genio, no obstante la incomprensión de la mayoría.

Algunos pasajes de la tercera Consideración intempestiva le han valido al ideal de perfeccionismo nietzscheano la acusación de no ser otra cosa que un elitismo estetizante que prevé la existencia de hombres de clase A, más dotados por naturaleza y destinados a alcanzar resultados brillantes en el campo del arte, y hombres de clase B, que deben reconocer que están menos dotados y se deben poner al servicio de los primeros. Esta es en

1 Para un caudro exhaustivo del sistema educativo nacionalista, estatalista y militarista contra el que Nietzsche dirige su crítica, ver Cooper 2011, 23-28. 
pocas palabras la interpretación de Rawls (1971), que luego será seguida por Hurka $(1993,2009)$ y otros. En realidad, en la base de esta interpretación hay numerosos malentendidos, bastante difíciles de desenmascarar. ${ }^{2}$ Ante todo, Nietzsche no entiende por cultura el reino de la literatura y de las bellas artes, como supone Rawls.

En El nacimiento de la tragedia Nietzsche imputaba la decadencia de la cultura de su época al poder excesivo conquistado por el espíritu científico. Como correctivo, auspiciaba una especie de «educación estética» de la humanidad. ${ }^{3}$ Gracias a sus artistas, los griegos habían conseguido soportar el carácter trágico de la existencia sin consolaciones ultraterrenas. «Las tragedias griegas -afirma Schacht - habían educado [a los griegos] su sensibilidad y autoconciencia, y les habían mostrado una forma de aceptar las duras realidades de la vida sin sucumbir a la náusea y a la desesperación» (Schacht 1998, 319). Wagner es el artistita que Nietzsche espera que asuma este papel en la época moderna. El «Sócrates músico» que Nietzsche imagina en El nacimiento de la tragedia (NT § 15) es precisamente el hombre del futuro que, conociendo las perniciosas consecuencias del poder excesivo de la ciencia sobre el arte, produce música para reequilibrar la relación entre las dos. ${ }^{4}$ En la tercera Consideración Intempestiva, ha cambiado mucho respecto a este escenario. Aunque públicamente Nietzsche todavía soporte el proyecto wagneriano, basado en la metafísica schopenhaueriana del genio artístico, en él se abre camino prepotentemente una visión completamente opuesta tanto del genio como de la cultura, así como del modo de llevarse a cabo una reforma cultura. Afirma muy claramente que la cultura es formación de la personalidad individual destinada a maximizar los talentos de un individuo, es decir su «genio» particular. Los «verdaderos hombres» que la cultura aspira a formar son individuos que viven como tales y no como animales, es decir, dominados por la codicia, por la necesidad y por el instinto gregario. Vivir como un individuo significa ser capaz de expresar juicios en primera persona y de elegir autónomamente la propia conducta de vida. Significa elegir hacer de la propia vida un fin y no un medio, o sea, no obrar en vistas al bien del Estado,

2 Para una discusión más profunda del perfeccionismo nietzscheano ver: Zavatta 2022.

3 Schacht (1998) identifica una refererencia por parte de Nietzsche a la educación estética propuesta por Schiller.

4 Church (2006) argumenta que el arte que Nietzsche invoca para corregir el cientificismo de la época no es simplemente la práctica de producir obras de arte, sino la práctica más importante de regular las pasiones. El símbolo de la pedagogía nietzscheana sería, por lo tanto, según Church, en última instancia, no el músico Sócrates, sino el Sócrates del Fedro, que va a morir con valentía y moderación (Church 2006, 698). En nuestra opinión, este significado del arte emerge completamente sólo de las Intmpestivas En El nacimiento de la tragedia Nietzsche aboga principalmente por una visión del arte como una bella ilusión que hace soportable la tragedia de la existencia. 
de la lógica del mercado, o para aumentar la ciencia. Significa dedicarse a sí mismo y a aquella que se siente ser la propia vocación confiando en el propio potencial e independientemente del juicio de los demás. La nueva idea de educación que Nietzsche propugna en este panfleto consiste por lo tanto sustancialmente en una «liberación» (SE 1), es decir, usando una metáfora biológica, en liberar a una planta de todos los hierbajos, escombros y gusanos que quieren dañar la raíz, de manera que esta pueda crecer y desarrollarse plenamente. Ser grande, declara Nietzsche claramente, no significa otra cosa que «ser libremente y completamente sí mismo» (SE 3). Nietzsche confiere al artista un papel privilegiado respecto a los llamados hombres comunes solamente porque este, contrariamente a ellos, ha encontrado el coraje para liberarse de las opiniones de los demás, afrontar heroicamente las desventajas sociales que esto comporta, y desarrollar aquella «unicidad productiva» (SE 3) de la que todo ser humano está dotado.

Los seres humanos son aún más perezosos que miedosos, y a lo que más miedo tienen es, precisamente, a las cargas que le supondrían una sinceridad y una desnudez incondicionales. Los artistas son los únicos que odian este indolente seguir haciendo camino sirviéndose de maneras prestadas y opiniones impuestas y desvelan el secreto [...] la tesis que dice que toda persona es un milagro irrepetible [...] más aún, se atreven a afirmar que en estricta consecuencia con esta singularidad suya, el ser humano es hermoso y digno de consideración, nuevo e increíble como cada una de las obras de la naturaleza, y que de ningún modo es aburrido (SE 1, OC I 749)

Este pasaje confirma por encima de toda duda razonable que Nietzsche se ha distanciado ya de la metafísica schopenhaueriana del genio que ve a este último como un superdotado, destinado a asumir un papel de líder cultura al que los hombres comunes no pueden hacer otra cosa que someterse. Más bien, anticipando la crítica de esta acepción del genio, la cual se completará en Humano, demasiado humano, Nietzsche entiende aquí por genio la mezcla de talentos que hace que cada ser humano sea único e irrepetible, y por tanto dotado de un valor absoluto. Schopenhauer, como filósofo-artista, no es exaltado por un don superior, sino por su conducta de vida, dedicada a la expresión de su talento peculiar. Simplemente siguiéndose a sí mismo, él se eleva al papel de ejemplo moral, y por lo tanto de educador.

Podemos concluir que, mientras las tradicionales prácticas pedagógicas consisten esencialmente en una transferencia de conocimientos del maestro al alumno y están por lo tanto fundadas en la diligencia y el respeto, para Nietzsche el verdadero educador es aquel que desencadena y facilita el proceso de puesta en discusión del propio modo de vivir, exploración de sí y de su potencial no expresado, y que este proceso está dirigido a la formación de la personalidad 
original que se expresa sin temor. Obviamente, si la enseñanza es ser uno mismo o, más propiamente, llegar a ser lo que se es, la única metodología a través de la cual puede ser enseñado es el ejemplo indirecto de quien ha vivido originalmente. A partir de la tercera Consideración intempestiva Nietzsche transfiere por lo tanto la responsabilidad de la educación de las instituciones al individuo singular, que debe hacerse cargo de su propia trayectoria educativa desde el principio hasta el fin. Nietzsche está convencido de que el surgir del genio podrá llegar solamente contra las instituciones educativas actuales, las cuales promueven inevitablemente la masificación y el conformismo. Es el individuo el que debe «elegir» entre los grandes hombres del pasado o del presente quiénes serán sus educadores.

Pero ¿cómo nos encontramos de nuevo a nosotros mismos? [...]. Que el alma joven mire en retrospectiva su vida planteándose esta pregunta: ¿qué has amado hasta ahora con veracidad, qué ha atraído tu alma, qué la ha dominado y al mismo tiempo colmado de felicidad? Ponte ante ti la serie de estos objetos venerados, y quizá a través de su ser y de su respectiva continuación te ofrezcan una ley, la ley fundamental de tu propio sí-mismo (Selbst). (SE 1, OC I 751)

En otras palabras, los propios educadores serán las figuras de los grandes hombres que la mayoría de las veces «nos hablan de nosotros», es decir resuenan más con nuestra experiencia porque poseen características que pertenecen a lo que uno siente que es su «yo más elevado». Esto puede imaginarse como la versión mejor de uno mismo a la que continuamente tendemos. En resumen, se trata de una especie de ideal regulativo que orienta nuestro obrar. Cavell lo define como un «sí mismo todavía no alcanzado, pero alcanzable».(Cavell 1990: 12) Mientras Conant, todavía de un modo más preciso, invita a pensarlo «como una serie de yoes alcanzables, cada uno, una vez alcanzado, conduciendo hacia un sucesor más inalcanzable pero todavía alcanzable» (Conant 2001, 234). Es solamente a través del encuentro de nuestro «yo más elevado» con el otro, es decir con una personalidad ejemplar, como podemos darles un giro y medir la distancia que separa nuestro yo actual de este yo posible.

II. DAR UN ESTILO AL PROPIO CARACTER: DOMINIO DE Sí FRENTE A LA TIRANÍA SOBRE LOS INSTINTOS

Así como la tercera Consideración Intempestiva no discute la filosofía de Schopenhauer, igualmente la cuarta Consideración Intempestiva no habla de la visión artística de Wagner, sino de la enseñanza que su conducta de vida imparte a quien lo observe. Lo que fascinó al joven profesor de Basilea, que ya conocía la música de Wagner y que lo apreciaba moderadamente antes de su 
encuentro en 1868, fue de hecho la potente personalidad del músico. Cuando Nietzsche escribió Wagner en Bayreuth, su distanciamiento del Maestro era ya inminente. Este escrito, que originariamente debía decir adiós a la empresa de Bayreuth, representa, al contrario, la última advertencia lanzada por Nietzsche al músico de Tribschen, es decir, al guía espiritual de aquella pequeña comunidad aristocrática que habría debido promover el renacimiento cultural alemán, antes de ser corrompido y esclavizado por todo lo que giraba en torno al «Reich», «cristianismo», «Bismarck», «éxito». (EH La intempestivas 1, OC IV 821).

El Wagner fuertemente idealizado que Nietzsche nos presenta en la cuarta Consideración intempestiva, es ante todo, así como Schopenhauer, ejemplo de confianza en sí mismo, capacidad de cultivar un pensamiento original y de decidir por sí mismo los valores con los que orientar la propia vida. Nietzsche afirma:

y el ejemplo [...] de Richard Wagner, muestra cómo el genio no debe tener miedo de entrar en la contradicción más enconada con las formas y órdenes existentes, si quiere sacar a luz el orden y la verdad superiores que viven en él. (SE 3, OC I 758)

\section{Observa Nietzsche:}

Cada uno de sus impulsos tendía a lo inconmensurable, todos sus talentos, gozosos de existir, querían soltarse individualmente y satisfacerse por separado; cuanto más grande era su abundancia, tanto más grande era el tumulto y tanto más hostiles las relaciones entre ellos. (WB 3, OC I 812)

La sobreabundancia de fuerza presente en una naturaleza ardiente y pasional, en la cual se agitan una gran cantidad de instintos que buscan cada uno obtener el mando, constituye según Nietzsche el punto de partida indispensable para la construcción de un gran hombre. Sin embargo, a medida que aumenta la agitación interna, crece también el peligro de perder el control de sí. Como Nietzsche observará en un fragmento de 1888, «las formas más ricas y complejas - pues la expresión "tipo superior" no dice sino eso perecen más fácilmente». (FP 14 [133] primavera 1888, FP I 568). Es por eso que, cuanto mayor es la agitación interna de un individuo, tanto más se aprecia la fuerza plástica que lo compone y lo resuelve en una forma artística superior. Nietzsche escribe sobre Wagner: «Es un placer observar ese proceso; en todos los aspectos fue creciendo, llevando las cosas hacia él y haciendo que se desarrollaran desde él, y cuanto más grande y más pesado era el proyecto, con tanta mayor fuerza se fue tensando el arco de un pensamiento que todo lo ordenaba y dirigía.» (WB 3, OC I 814). Aunque en las obras sucesivas Wagner y su ópera sean definidas como la quintaesencia de la décadence 
moderna (CW 5, OC IV 582), en la cuarta Consideración intempestiva el músico, al contrario, asume el papel de ejemplo admirable del dominio de sí. En lo específico, el Wagner de la cuarta Intempestiva es ejemplo de un tipo de dominio de sí muy diverso de aquel realizado a través de la tiranía de la razón sobre los instintos, típico del ideal ascético. El ideal ascético que nutre la moral cristiana valora nuestras pulsiones animales como «malvadas» y prescribe su represión o supresión. Pero alcanzar el control de sí mismo reprimiendo los propios instintos naturales es, sostiene Nietzsche, un empobrecimiento insostenible, que priva al hombre de la energía para conseguir cualquier objetivo. ${ }^{5}$ En una nota tardía Nietzsche presenta tanto el dar rienda suelta a las pasiones como el suprimirlas como dos formas de estupidez.

Todas las pasiones tienen una etapa en que son simplemente nefastas, en que, con el peso de la estupidez, [...] En otro tiempo, a causa de la estupidez que había en la pasión, se hacía la guerra a la pasión misma: la gente se conjuraba para aniquilarla[...] Aniquilar las pasiones y apetitos simplemente para prevenir su estupidez y las consecuencias desagradables de esta estupidez suya, eso hoy día se nos aparece simplemente incluso como una forma aguda de estupidez».(GD, La moral como contranaturaleza $\S 1$, OC IV 635).

Entre los dos extremos mencionados anteriormente, igualmente nocivos, Nietzsche introduce más bien la alternativa de subyugar, refrenar, sublimar las pasiones de tal modo que estas sirvan al fin que queremos perseguir. ${ }^{6}$ Quien consigue el dominio de sí de este modo, de manera distinta a quien tiraniza los propios instintos, será un individuo que tiene a disposición una gran energía propulsiva. ${ }^{7}$ En definitiva, a través del Wagner idealizado de la cuarta Intempestiva Nietzsche añade una especificación adicional sobre cómo llegar

5 Ver también FP IV 587, 1888 14[163] Nietzsche considera la represión de los instintos una «locura» [Wahnsinn] y observa que el efecto de esta operación es el de convertir al hombre moderno en pasivo, cobarde y mediocre. En el primero de los tres ensayos que componen la Genealogía de la moral, Nietzsche observa que el ser humano hecho «bueno», es decir «que ya no es peligroso», si es cierto que ya no inspira miedo, también es cierto que ya no inspira respeto: «con el miedo al hombre hemos perdido también el amor a él, el respeto profundo por él, la esperanza e incluso la voluntad de él»(GM I 12, OC IV 475.).

6 Véase también FP IV 61, otoño 1885, - primavera 1886 1[122] y FP IV 487, 1888 14[163]. Como escribe Reginster: «El impulso dominante logra el dominio sobre los impulsos dominados, no cuando los reprime o los desvía de la búsqueda de sus propios fines específicos [...] Logra la maestría, más bien, cuando logra integrar las búsquedas y actividades distintivas de los impulsos dominados [...]... [en] la búsqueda de su propio fin específico. El impulso dominante, en otras palabras, permite la expresión de los impulsos dominados, aunque dentro de las limitaciones establecidas por la búsqueda de su propio fin» (Reginster 2003, 76)

7 Ya en una nota de 1881 Nietzsche ilustra la diferencia entre dominio y tiranía de sí como la capacidad de sublimar en vez de erradicar los propios impulsos animales. (FP II 795, 1881, 11[169]). Ver también FP IV 466, 1887-1888 11[353], y FP IV 277, otoño 1887, 9 [139]. 
a una plena y auténtica expresión de sí: no solo es necesario identificar el talento que nos hace únicos y cultivarlo vigorosamente, independientemente de la fama y el éxito. Quien quiera alcanzar su «más alto yo», es decir vivir al máximo de sus posibilidades, deberá también llegar a ser capaz de gobernar las propias pulsiones internas y someterla a sus propios fines.

Esta autoeducación o autodisciplina que Nietzsche explica a través de las figuras idealizadas de Schopenhauer y Wagner es presentada, como se lee en Ecce Homo, no solo como alternativa necesaria, sino incluso como defensa contra la acción educativa institucional. Es importante subrayar dos factores. En primer lugar, esta es auto-impartida, eligiendo por sí mismo sus ejemplos. Además, no consiste en un conjunto de doctrinas o de teorías, sino en una práctica de vida que se aprende a través del ejemplo. Tal camino de autoeducación o auto-disciplina conduce al individuo a "alcanzar la grandeza» (EH Intempestivas 3, OC IV 823), lo que, según Nietzsche, no significa otra cosa que «llegar a ser lo que se es», o sea, expresarse a sí mismo de forma auténtica y plena. Claramente, ya que nuestro potencial no se conoce de antemano, este objetivo se traduce en un ideal regulativo, en otras palabras, en el imperativo de tender en cada momento hacia aquella que nos parece como la mejor versión de nosotros mismos.

\section{ZRATUSTRA Y EL IDEAL DE SUPERHOMBRE}

«Yo os enseño el Superhombre» [Ich lehre euch den Übermenschen]" (Za Prologo 3, OC 73) ${ }^{8}$ : estas son las palabras con las que Zaratustra se presenta a la gente reunida en la plaza del mercado en el Prólogo del que Nietzsche ha definido como «el mejor de mis libros» (CO IV 313-315, n. 370, 372) y «el punto más alto » de toda su obra (CO IV 318, n. 375). ¿Quién es el superhombre que ha sido objeto de tantas interpretaciones? Hoy los estudiosos están al menos de acuerdo en el hecho de que se trata del ejemplar de una especie superior. Ya en 1903 Oskar Ewald describía al superhombre en los siguientes términos:

El superhombre no debe ser concebido en absoluto de acuerdo con una analogía con la humanidad viva, no debe entenderse simplemente con órganos enriquecidos y dotado de una constitución más sana que lo preserve de las imperfecciones del homo sapiens. No es una figura de piedra o metal, que se eleva sobre las nubes e invite a experimentos aeronáuticos. De hecho no es un objeto que pueda ser pensado con evidencia concreta y que posea una apariencia

8 Stolz (2017) es uno de los pocos intérpretes que también presta atención a la otra enseñanza de Zaratustra, a saber, el pensamiento del eterno retorno (véase también Gordon 1980 y Schacht 1998, 323). Stolz también menciona las posibles aplicaciones de esta enseñanza dentro de la teoría contemporánea de la educación. 
sensible adecuada, sino un símbolo, una categoría del pensamiento y del querer moral (Ewald 1903, 29-30).

Siguiendo la dirección inaugurada por Ewald, el superhombre ha sido imaginado no como algo realmente existente, sino como un ideal regulativo que impele a cada uno a trascenderse a sí mismo. En definitiva, se trata de otro nombre para lo que en la tercera Intempestiva Nietzsche llamaba «higher self». La enseñanza nietzscheana del superhombre puede ser leída como otra manera de presentar el proyecto del perfeccionamiento infinito de uno mismo o autosuperación (Selbt-Überwindung) que Nietzsche había anunciado en las Intempestivas y que continúa desarrollando en su filosofía del espíritu libre.

Como Schopenhauer, Zaratustra es un ejemplo de anticonformismo en la medida en que se eleva más allá de las masas para vivir según los propios valores. Como Wagner él está dotado de una gran riqueza de instintos naturales pero, al mismo tiempo, también de la capacidad de controlarlos y gestionarlos de manera efectiva. ${ }^{9}$ Distintamente de las figuras idealizadas de Schopenhauer y Wagner que Nietzsche retrata como educadores involuntarios e inconscientes en las Intempestivas, Zaratustra, sin embargo, se coloca explícitamente como tal. Es presentado por Nietzsche como «un educador dedicado, sensible, valiente y creativo» (Gordon 1980, 191). Sin embargo, no debemos pensar que Nietzsche haya cambiado de idea respecto a la figura del educador. Como subraya Schacht $(1998,323)$, el verdadero educador aquí no es ni Nietzsche ni Zaratustra, sino más bien «the work itself». Daniel Conway (1990) explica que Así habló Zaratustra puede ser visto como una especie de novela de formación en la que el protagonista, en el curso de la historia narrada, llega a reconocer que aquello que tiene que enseñar exige abandonar el papel tradicional de maestro. ${ }^{10}$ En otras palabras, Zaratustra comprende que si debe enseñar el superhombre, no puede presentarse como una figura autoritaria que imparte doctrina. Ya desde el primer libro él se presenta en el papel paradójico de un anti-maestro. Parodiando a Cristo que regaña a los discípulos por haber

9 Zaratustra aprendió que para obtener el superhombre, todos los instintos son necesarios, incluso los tradicionalmente considerados malvados (Za III, El Convaleciente 2). Así como el rayo ya no solo no es destructivo para Zaratustra, sino que está esclavizado a su voluntad, sus instintos animales se convierten en el combustible para lograr sus altos objetivos (Za IV, Del Hombre Superior).

10 En los años de madurez, la idea de educación de Nietzsche, señala Schacht (1998), ya no es la de El nacimiento de la tragedia. En esta obra, de hecho, Nietzsche fundó la posibilidad de la afirmación de la existencia en la ilusión artística. En cambio, «Zaratustra se basa en la convicción de que la desilusión radical, la veracidad intransigente y la afirmación de la vida sin reservas son humanamente posibles juntas»(Schacht 1998, 323). «En un sentido amplio», continúa Schacht, «se puede decir que la tarea de Zaratustra consiste en el proyecto educativo de cultivar una sensibilidad capaz de pasar la "prueba de la repetición", y así afirmar la vida bajo lo que Nietzsche considera la más desalentadora de las descripciones posibles» (Schacht 1998, 323). 
olvidado sus enseñanzas después de su muerte, Zaratustra exclama: «solo cuando todos me hayáis negado, querré volver entre vosotros» ( $\mathrm{Za} \mathrm{I} \mathrm{De} \mathrm{La}$ virtud que hace regalos 3, OC IV 117). Zaratustra explica a los discípulos que demostrarán que han entendido su enseñanza solo cuando dejen de seguirlo, de idolatrarlo, de imitarlo y se concentren más bien en la tarea de llegar a ser sí mismos. Todavía en el libro III, parodiando el pasaje del Evangelio en el que Cristo exhorta a sus discípulos para que le sigan con las palabras: «Yo soy el camino, la verdad y la vida», Zaratustra aleja a sus seguidores con estas palabras: «Este - es ahora $m i$ camino, - ¿cuál es el vuestro? [...] iEl camino directamente, - no existe!» (Z III Del espíritu de la pesadez 2, OC IV 192). Como he subrayado anteriormente, si la enseñanza es la de llegar a ser individuos, solo persiguiendo el propio camino es como se puede demostrar que se ha comprendido bien. Lo que Zaratustra espera de sus discípulos es que estos, lo mismo que él, encuentren su camino y aprendan a hacerse creadores de sus propios valores. ${ }^{11}$

En la relación de Zaratustra con sus discípulos, o los que se dicen tales, que efectivamente evoluciona desde el principio al final de la historia, se puede ver una referencia autobiográfica a la historia de Nietzsche como educador. Así como Zaratustra inicialmente se enfrenta a la gente en la plaza del mercado, el Nietzsche de Basilea confía en el proyecto wagneriano de un renacimiento de la cultura alemana en su conjunto. Él espera que surjan nuevas instituciones nueva y más ilustradas que se ocupen de promover al individuo superior. Desilusionado por el modo en el que se ha realizado concretamente el proyecto de Bayreuth, en 1876 Nietzsche se refugia en Sorrento con algunos amigos y sueña con fundar una comunidad de educadores, donde estos se eduquen unos a otros, es decir que se estimulen recíprocamente en la búsqueda de la excelencia. (Ver D’Iorio 2012). Del mismo modo, Zaratustra invita a unos pocos discípulos seleccionados a que le sigan a la Isla de las Bienaventurados $\mathrm{y}$, durante algún tiempo se engaña de haber finalmente encontrado la dimensión correcta. Al final se da cuenta de que esta no puede ser una solución practicable por algún tiempo, sino solamente una huida de la realidad. Para afirmar el eterno retorno, es decir para decir sí a la vida y al mundo tal y como son, Zaratustra necesita abandonar a sus amigos. Pero él no vuelve a predicar en la plaza del mercado. Más bien se va a las alturas, y espera que los hombres superiores vengan a él, tomando como peces el

11 Robert Pippin sostiene que Zaratustra es presentado por Nietzsche como un maestro que, al final de la historia, concluye que la tarea que se ha propuesto es imposible. Esto se debe a que, según Pippin, Zaratustra, por un lado, proporciona enseñanzas, por otro lado socava su autoridad al cuestionar la posibilidad de concebir la verdad en el sentido tradicional del término (Pippin 1988, 56). No estamos de acuerdo con la interpretación de Pippin, ya que este argumento debería extenderse a todos los libros escritos por Nietzsche. 
anzuelo de su felicidad (Z IV La ofrenda de la miel, OC IV 218). En otras palabras, así como Nietzsche al final se da cuenta de que lo mejor que lo que uno pueda hacer por los otros es vivir su propia existencia al máximo de sus posibilidades, empeñándose únicamente en realizarse auténtica y plenamente a sí mismo. Vivir para sí mismo, buscar la propia felicidad en la realización de sí y desaprender a hacer el mal a los otros (Za II De los compasivos) son en definitiva el mayor bien que podemos hacernos a nosotros mismos y a la comunidad en la que vivamos, y la enseñanza más importante que podamos dirigir a los demás.

Hasta mi felicidad la lanzo a todas las lejanías, entre el amanecer, el mediodía y el atardecer, a ver si muchos peces humanos no aprenden a tirar de mi felicidad [...] Ése soy yo, en efecto, desde el fondo y desde el principio, atrayendo, levantando, elevando, tirando; alguien que tira, cría y corrige, que no en vano se dijo una vez a sí mismo: “¡Llega a ser quien eres!” (Za IV La ofrenda de miel, OC IV 219).

Para ilustrar todavía mejor la posición a la que llega Nietzsche en los años de madurez es útil citar una carta dirigida a su hermana Elisabeth en 1883:

Lo que me repugna de ESTA época es su indecible flaqueza, afeminamiento, falta de personalidad, volubilidad, bonachonería, en suma, la debilidad del «ego»ismo, que incluso querría disfrazarse de «virtud». Lo que me ha beneficiado hasta ahora ha sido la visión de personas de voluntad tenaz [...] y que son tan honestos como para creer sólo en el propio yo y en el propio querer, e imprimirlos en la humanidad para todo futuro. ¡Pardon! Esto era lo que me atraía de Richard Wagner; y también Schopenhauer vivía sólo con este estado de ánimo.[...] Hay unos «yos» FUERTES cuyo egoísmo estaríamos tentados a definir como divino (p. ej. Zaratustra) (CO IV n. 471) $)^{12}$

Nietzsche individua el valor que él tanto admira en Schopenhauer y Wagner - y del que por otra parte deplora su ausencia en los hombres de su época - en el egoísmo. Y es este mismo egoísmo el que encarna en el personaje de ficción de Zaratustra. Egoísmo obviamente es aquí entendido no en la acepción schopenhaueriana, es decir como antojo insaciable de los bienes materiales para obtener los cuales el individuo emprende una lucha contra sus propios semejantes. Más bien, el egoísmo alabado por Nietzsche es una concentración sobre sí mismo y sobre la propia perfección, dirigida a alcanzar la máxima expresión de la propia naturaleza. Este segundo tipo de egoísmo reporta realmente un beneficio a toda la humanidad. Al contrario, la moral del altruismo y de la compasión que domina la modernidad no hace más que debilitar la personalidad de quien la ofrece y de quien la recibe. (Za II De 
los compasivos). La transvaloración de los valores de egoísmo y compasión, prefigurada en las figuras idealizadas de Schopenhauer y Wagner, se lleva a cabo en la figura de Zaratustra, es desarrollada por Nietzsche en las obras que exponen su filosofía del espíritu libre. En el aforismo 95 de Humano, demasiado humano, titulado Moral del individuo maduro, Nietzsche observa cómo en la sociedad moderna el altruismo se alaba frente al egoísmo como si únicamente la colectividad pueda sacar beneficio de él.

Hasta ahora se ha considerado como verdadero signo distintivo de la acción moral lo impersonal; y se ha demostrado que en el origen fue la consideración de la utilidad general la que sirvió de base para alabar y honrar todas las acciones impersonales. (OC II 114)

Nietzsche considera más bien el altruismo como una gran mistificación de la que no pueden beneficiarse ni los individuos ni la sociedad. Es al contrario, «en la consideración más personal posible», afirma, donde «descansa también la mayor utilidad para la colectividad». La moral del individuo maduro que él propone como alternativa a la moral de la compasión y del altruismo puede ser resumida, en definitiva, en la formula siguiente: «Hacer de sí mismo una persona completa $\mathrm{y}$, en todo lo que se hace, tener presente el máximo bien para ella - esto hace avanzar mucho más que las inclinaciones y acciones compasivas hacia los demás». Ofrecerse «en holocausto al Estado» o « a todo lo que necesitaba ayuda» es realidad solo un paliativo, que no hace más que aumentar los males de la sociedad. (Ibid.) $)^{13}$

Quien se dedica a su perfeccionamiento, trae indirectamente beneficios también a los que pueden disfrutar de los frutos de este proceso. Además y esto es el punto que sobre todo nos interesa- el individuo maduro es un

13 En La gaya ciencia Nietzsche llevará a cabo una severa crítica de la compasión y el altruismo, mostrando cómo estos 1 . no surgen de un interés sincero en el bienestar del otro, sino del deseo de afirmar la propia superioridad; 2 . no aportan ninguna ayuda real a la persona que sufre, sino que añaden humillación a su sufrimiento; 3 . evitar que el otro se fortalezca pasando por dificultades; 4. desperdician tiempo y energía preciosos en aquellos que los ofrecen, que podrían usarse mucho más útilmente para perfeccionarse (GS 338, véase también GS 99, Za II Dioses compasivos, GM Prefacio 5). Por otro lado, continúa enfatizando la posibilidad de entender el egoísmo de una manera diferente al significado tradicional en el que se usa este término. En Zaratustra Nietzsche caracteriza el primer tipo de egoísmo como «un egoísmo mezquino, que siempre quiere robar» (Za I, De la virtud que hace regalos, 1). En cambio, se dirige a aquellos que poseen el segundo tipo de egoísmo en estos términos: «Vuestra alma aspira, insaciable, a los teoros y a las joyas, porque vuesta virtud es insaciable en su voluntad de regalar. /Obligáis a todas las cosas a ir hacia vosotros y a entrar en vosotros, para que broten luego de vuestro manntial como dones de vuestro amor». (Za I, De la virtud que hace regalos, 1, OC IV 115). En última instancia, Nietzsche no quiere que el individuo se sirva a sí mismo en lugar de al «bien general», como argumenta Minsk $(2004,164)$. Más bien, Nietzsche invita al individuo a elaborar un ideal más alto que su propio interés y a considerar cómo perseguirlo coincide con la búsqueda final del bienestar de la sociedad en su conjunto. 
estímulo y un ejemplo para quien lo observa. En otras palabras, sin ocuparse directamente de ellos y simplemente viviendo su vida, él ofrece a ellos la mayor ayuda, es decir un sostén en el tormentoso proceso de llegar a ser aquello que se es. Coherentemente con esta visión, el educador ideal es para Nietzsche no alguien que se prodiga por sus alumnos, sino el individuo que vive para sí mismo lo mejor que puede, estimulando de esa manera indirectamente a quien lo mira para hacer lo mismo.

En definitiva, también en el Nietzsche maduro la idea de educación no solamente implica una total transvaloración de las tradicionales prácticas educativas basadas en una transferencia de conocimiento - intencional y explícito - de maestro a alumno. Realmente, falta el concepto mismo de pacto educativo, en el que el maestro se empeña en enseñar y el alumno en aprender. De hecho, el maestro no es consciente de ser tal, ni interesado en enseñar nada. Él llega a ser indirectamente e inconscientemente educador de otros en la medida en que consiga darse a sí mismo una autodisciplina, que lleve finalmente a ser auténtica y plenamente sí mismo.

\section{CONCLUSIÓN}

Examinando la filosofía de Nietzsche, muchos intérpretes han concluido:

1) que en ella no se encuentra ninguna instrucción útil ni respecto a posibles contenidos de enseñanza, ni respecto a posibles metodologías. Johnston (1998) argumenta de una manera muy elocuente que en la filosofía de Nietzsche, «no hay lugar para una discusión razonada de las técnicas o el contenido de la autosuperación, más allá de las opiniones generales que el propio Nietzsche ofrece con respecto a este objetivo. No hay métodos de instrucción "compartidos", no hay currículos que puedan ser examinados, no hay contenidos que descubrir. Solo está el individuo, inventando estas reglas a medida que él o ella avanza» (Johnston 1998, 83. Ver también Allen 2017, 202-203).

2) Que Nietzsche aboga por una educación elitista, y por lo tanto nada de cuanto propone puede ser adoptado dentro de instituciones democráticas. Esta línea es seguida, por ejemplo, por Fennell (2005). Basándose en un discutido pasaje de la tercera Intempestiva («¿cómo adquiere tu vida, la vida del individuo, el valor más alto, el significado más hondo [...] de una sola manera, a saber, que vivas en provecho de los ejemplares más raros y valiosos...». (SE 6, OC I 780), Fennell sostiene que, según Nietzsche, debería haber distintos tipos de educación para diferentes tipos humanos. Mientras la élite spiritual necesita una pedagogía que los libere de los valores mortificantes del rebaño, el rebaño tiene que estar formado para garantizar a la colectividad una estabilidad económica y social. Sobre esta base, Fenell (2005) 
concluye que la pedagogía nietzscheana es totalmente inutilizable en un escenario democrático como el actual.

Una versión alternativa pero siempre elitista de la filosofía educativa de Nietzsche se encuentra en Jonas (2008). Este se opone a Fennel (2005) con el argumento de que, según Nietzsche, el ideal de autosuperación o perfeccionamiento de sí puede y debe ser propuesto a todos. Sin embargo desde el principio Nietzsche, según Jonas, es consciente de que eso producirá resultados diversos. Mientras la élite espiritual aprenderá a producir obras de arte, la masa aprenderá «a cómo admirar el poder y la belleza» (Jonas 2008, 166), superando el resentimiento hacia los más dotados. Esto es lo que Jonas (2008) también espera de la adopción del ideal de autosuperación nietzscheano en la didáctica contemporánea: empujar a los más dotados a sobresalir, y a los menos dotados a apreciarlos.

Respecto al punto 1) no podemos no coincidir con Johnston (1998) respecto al hecho de que, después de una incipiente esperanza en la posibilidad de cambiar las instituciones educativas, Nietzsche llegue a la conclusión de que la educación en la individualidad deberá ser alcanzada por cada uno a través de un camino propio, que nadie puede enseñarle. Esto no significa, sin embargo, como concluye por el contrario Johnston, ni 1.1) que las ideas de Nietzsche no puedan inspirar nuestras prácticas educativas, ni 1.b) que debemos renunciar a todo proyecto educativo.

Respecto a la posibilidad de aplicar las ideas nietzscheanas a la didáctica contemporánea (1.a), el concepto más debatido es el de la autosuperación. Muchos autores consideran que la inclusión de tal ideal entre los objetivos didácticos no sea absolutamente deseable. Del análisis realizado en este ensayo, sin embargo, nos parece que esta conclusión es tratada sobre la base de un sustancial malentendido de tal ideal. Según Aviram (1991) el superhombre de Nietzsche - que encarna el ideal de superación - es aquél que ha reconocido el hecho de que cada uno conoce el mundo desde una cierta perspectiva y que tal perspectiva cambia continuamente. En otras palabras, según Aviram, el superhombre es aquel que reconoce que su perspectiva es arbitraria, parcial y sobre todo temporal. Así como la propia identidad es de vez en cuando definida por la perspectiva que adoptemos, el superhombre - concluye Aviram - sería aquel que está en grado de «eliminar su ego subjetivo» (Aviram 1991, 223) y de «reconocer que él no tiene un identidad particular». (Aviram 1991, 224). Como observa justamente Jonas $(2008,159)$, cambiar la perspectiva y abrazar varias, en realidad, es para Nietzsche un proceso que no lleva a negar o a perder la identidad, sino a reforzarla (ver también Zavatta 2019).

Otro malentendido del ideal nietzscheano de autosuperación es evidente en la interpretación de Rosenow (1989). Según Rosenow el proceso de 
autosuperación de Nietzsche se opone al concepto tradicional de «selfmastery or self-control» (Rosenow 1989, 308-309). Este último es entendido por Rosenow como control de las pasiones por parte de la razón con el objeto de soportar la moralidad y las convenciones sociales. La autosuperación invocada por Nietzsche consistiría por tanto en abdicar de la razón y dar libre curso a los «siniestros impulsos» (Rosenow 1989, 311) del ser humano. Además, evolucionar continuamente, es decir, cambiar periódicamente todas nuestras creencias, valores, ideales, junto con las relaciones humanas que se entrelazan en torno a estos, es juzgado por Rosenow (1989) como un objetivo psicológicamente insostenible. Sobre esta base, Rosenow sostiene que el ideal nietzscheano de la autosuperación es peligroso y destructivo, y no debe absolutamente ser introducido en nuestras políticas educativas. ${ }^{14}$ Frente a esta visión Jonas $(2008,2021)$ argumenta que en realidad el ideal de autosuperación coincide para Nietzsche con el antiguo ideal de dominio de sí, que debe lograrse, sin embargo, no a través de la violenta imposición de la razón sobre el instinto, sino más bien sabiamente coordinando todos nuestros impulsos hacia el logro de un fin unitario. Sobre esta base Jonas sostiene que «la filosofía de Nietzsche de la autosuperación proporciona una poderosa metodología de sí, para las aulas democráticas de estilo americano» (Jonas 2008, 154). ${ }^{15}$

Sobre la base del análisis de los textos nietzscheanos presentados más arriba, podemos afirmar que ciertamente la idea de una artística self-mastery es parte del ideal nietzscheano del superhombre. Sin embargo esto no excluye la idea - que igualmente pertenece a tal ideal - de una continua ampliación de la propia perspectiva y de un infinito proceso de actualización de posibilidades latentes. A mil millas de distancia de la concepción de Schopenhauer de la inmutabilidad del carácter, Nietzsche no prevé la existencia de un «verdadero sí mismo», es decir de un núcleo de la personalidad por descubrir y sacado a la luz. Más bien, el individuo está envuelto en un proceso de continuo cambio,

14 Rosenow (1989) con su ensayo quiere criticar a Hillesheim (1986), quien argumentó que «con la doctrina del hombre como algo "inacabado", como un ser con el potencial de poder siempre trascenderse, Nietzsche nos ha proporcionado el único ingrediente esencial de una filosofía de la educación: una visión de "lo que el hombre puede llegar a ser"” (Hillesheim 1986, 173). Respondiendo a la crítica de Rosenow (1989), Hillesheim (1990) muestra que está de acuerdo en que Nietzsche, con su ideal de la autosupración, quiere desafiar el concepto de «autodominio» o «autocontrol» en el que se basa el «pensamiento educativo tradicional» (Hillesheim 1990, 212

15 Jonas reconoce que el ideal de la autosuperación coincide esencialmente con el del perfeccionismo moral. Contra cualquier objeción a la pretensión de absolutizar un modelo de vida contra los demás, Jonas señala que este ideal es concebido por Nietzsche como una medida de la degradación moral de la vida moderna, donde reina soberanamente el ideal del placer fácil y sin consecuencias. (Jonas 2021, 10). Por lo tanto, no se trata de negar la pluralidad de valores y creencias, sino simplemente de afirmar la necesidad de que cada uno encuentre los suyos, es decir, formar su propia personalidad 
de continua autocreación, donde hay siempre una nueva potencialidad que realizar, un lado inexplorado de sí por revelar y expresar. ${ }^{16}$

Otro malentendido del ideal nietzscheano sobre la base del cual este ha sido considerado nocivo para las contemporáneas prácticas educativas es la visión según la cual tal ideal correspondería a una profesión de relativismo moral extremo, por el que el individuo se convierte en el árbitro indiscutible de lo que está bien y lo que está mal (Arcilla 1995). ${ }^{17}$ Sin embargo, como justamente subraya Cooper $(2011,3)$, el esfuerzo de cualquiera que se embarca en un camino hacia la individualidad es comprender «cómo vivir auténticamente» sin caer en el nihilismo. Después de haberse distanciado de la moral del rebaño, es extremadamente importante que el individuo encuentre su propio código moral y se convierta en legislador y juez de sí mismo. En definitiva, se trata de mantenerse alejado de las actitudes opuestas llamadas por Cooper «frivolidad»y «fanatismo», ambas expresiones para Nietzsche del nihilismo pasivo. (Cooper 2011, 5).

Un elemento extremadamente interesante de la filosofía de Nietzsche, que impide que el individuo que se separa de la masa absolutice su propia visión de las cosas y, por lo tanto, caiga en el solipsismo, es la confrontación con el otro. Claramente no con «cualquier» otro. Como hemos visto, el juicio del hombre-masa no debe influir en lo más mínimo en el camino de aquellos que aspiran a la individualidad. Más bien, la confrontación que busca este individuo es con su par, es decir, con aquellos que, como él, aspiran a la mejor versión de sí mismo.

Este individuo, que es reconocido por tener el mismo valor, es el amigo. Ningún intérprete hasta ahora ha destacado el hecho de que, en la filosofía de Nietzsche del período medio y maduro, la figura del amigo complementa de manera importante la del educador. De hecho, se puede

16 La continuidad entre las Intempestivas, la filosofía del espíritu libre y Así habló Zaratustra es declarada por el propio Nietzsche en una carta dirigida a Köselitz en abril de 1883, poco después de enviarle el primer Zaratustra. En la carta, Nietzsche proporciona a su amigo una clave de esta obra: «En "Schopenhauer como educador" todo esto ya había sido predicho, pero entre "Humano, demasiado humano" y "El superhombre" todavía quedaba un buen camino por recorrer» (CO IV 349, n. 405). Véase también la carta de Nietzsche a Overbeck de agosto de 1884 (CO IV 459, n. 524).

$17 \mathrm{Al}$ argumento de Arcilla (1995), Jonas contrapone lo siguiente: «Al igual que sus predecesores moralizantes, Nietzsche promueve la gracia, la justicia, la templanza, la honestidad, la generosidad, el civismo, la ecuanimidad, la gratitud, el coraje, la fidelidad, la magnanimidad y la esperanza. Pero la principal diferencia entre Nietzsche y la tradición moral contra la que se define es su creencia de que estas cualidades deben ser valoradas porque hacen que el mundo sea más hermoso ... - no porque maximicen la utilidad, sean buenas en sí mismas o sean ordenadas por Dios» (Jonas 2021, 12). Esta afirmación parece realmente difícil de apoyar. Nietzsche no proporciona criterios estéticos por los que un mundo «humanizado«, es decir, al que se atribuyen las características que desde cierto punto de vista han de considerarse virtuosas, pueden ser juzgadas "más bellas", y por tanto constituyen el objetivo de nuestra acción moral. 
decir que el amigo, si es auténticamente tal, se convierte en nuestro mejor educador en la medida en que nos impulsa a definir nuestra visión de las cosas y a cuestionarla. (Ver Zavatta 2008 y Zavatta 2019, 128-138). De un verdadero amigo no esperamos condescendencia, sino sinceridad, incluso cuando da lugar a un choque (Za I, Del amigo). El resultado es siempre y en todo caso un crecimiento, por lo tanto un paso adelante en el proceso de autoexpresión. Por eso, en Zaratustra, Nietzsche define al amigo como «un puente hacia el superhombre» (Za I, Del amigo). Para el objetivo de formar una individualidad poderosa, que evoluciona y se expande continuamente, la confrontación con personalidades diferentes a la propia es de hecho esencial. Uno podría inspirarse en este elemento de la filosofía nietzscheana para introducir en la enseñanza estrategias para estimular tanto la producción acumulativa de conocimiento como la evaluación por pares. Hasta la fecha, se ha demostrado que la práctica de la revisión por pares (que consiste en hacer que los estudiantes lean el trabajo de sus compañeros, evaluarlos y proporcionar a los compañeros de clase un feedback constructivo) mejora la capacidad de analizar, evaluar y sintetizar contenidos educativos. (Sadler \& Good 2006). Esta estrategia, empleada en el aula y en casa, en nuestra opinión a lo largo del tiempo también podría mejorar el espíritu de autocrítica del estudiante, la capacidad de considerar respetuosamente visiones alternativas a las suyas y entrenarlo para enfrentarse a los demás con serenidad y lealtad. En pocas palabras, el estudiante aprendería a reconocer las críticas dirigidas a su propia visión de las cosas o a su propio trabajo no como un ataque o una falta de respeto, sino como un estímulo precioso y una ayuda para crecer y mejorar.

En última instancia, nuestra posición es completamente opuesta a la de Johnston (1998) cuando afirma: «La producción de un ciudadano ilustrado, emancipador y democratizado es antitética a la autosuperación individual que Nietzsche defiende: uno que se despegaría de los vestigios de las valoraciones socioculturales para llegar a ser lo que él o ella es» (Johnston 1998, 82). Más bien, la educación propuesta por Nietzsche, que se configura como una educación de la individualidad a través de la confrontación con individualidades diferentes a las propias, es exactamente el requisito esencial para vivir en una sociedad democrática. ${ }^{18}$

Con respecto a la posibilidad de una educación de masas contra la que

18 Zakaras enfatiza que la individualidad es un requisito previo para el ciudadano de una sociedad democrática, ya que «la individualidad es la antítesis de la docilidad» (Zakaras 2009, 7). La docilidad, alabada como virtud en las formas antidemocráticas de gobierno, en las que el buen ciudadano es el ciudadano obediente, representa, por el contrario, el mayor peligro para una sociedad democrática. De hecho, conduce a la apatía y a la renuncia a la ciudadanía activa. Al volverse dócil, el ciudadano abdica de su responsabilidad en el contexto de las decisiones públicas y renuncia al control sobre quienes ejercen el poder político (Zakaras 2009, 11). En última instancia, las personas 
Nietzsche toma partido decisivamente (1.b), creemos que, en este caso, es muy necesario aprender de Nietzsche y, como él mismo prescribe, utilizar sus ideas contra sí mismo para formar una visión diferente y propia de las cosas. Como sugiere Bingham (2001), este proceso de rebelión «puede iniciarse tanto escuchando la filosofía de Nietzsche como ignorando sus afirmaciones sobre los detrimentos de la educación de masas» (Bingham 2001, 338). ${ }^{19}$

Convertirse en uno mismo, es decir, vivir como individuos, como señala acertadamente Cooper (2011), no es un proceso que el estudiante pueda emprender solo. Citando a Adorno, Cooper argumenta que «alentar a los hombres a buscar la autenticidad a través del esfuerzo personal o educativo» significa que los maestros abdiquen de su misión educativa que, a su vez, es indispensable para que puedan llevar una vida auténtica (Cooper 2011, 5). Cooper hace una larga disquisición sobre el significado que se debe dar a la palabra «auténtico» dentro de la filosofía de Nietzsche, específicamente cuando tal adjetivo se refiere a la existencia del individuo. En esencia, según Cooper, se puede decir que una conducta de vida es auténtica si se basa en valores que sentimos que hemos elegido y / o aprobado libremente. El mayor peligro a superar para vivir una vida auténtica es la tendencia a «dejarse vivir», o a vivir de manera «inconsciente», es decir, la «aceptación irreflexiva» de los valores impuestos por los demás (Cooper 2011, 4). Basándonos en nuestra investigación, podemos agregar que la capacidad de controlar y gobernar las pasiones de uno con miras a lograr un objetivo es, asimismo, la autenticidad, un componente indispensable de la individualidad. Obviamente, Nietzsche no proporciona ninguna instrucción con respecto al método a adoptar para lograr cualquiera de los dos objetivos, porque en su opinión la individualidad nunca será promovida por las instituciones educativas, sino perseguida por el individuo contra ellas ${ }^{20}$. Respecto a este punto coincidimos con Cooper cuando

dóciles «aceptan sin recelos ser utilizadas» con fines políticos y económicos que renuncian a entender (Kateb 1992, 22).

19 Según Bingham, «la crítica de Nietzsche a las instituciones educativas de su época [...] no está de acuerdo con la mayor parte de su filosofía». (Bingham 2001, 339). De hecho, Bingham señala: «El error de Nietzsche es que considera que la educación de masas está generalmente sesgada contra la auto-radicalización. Este tipo de postura con respecto a la educación es curiosamente anti-nietzscheana en la medida en que no es en absoluto genealógica, sin considerar completamente que la práctica humana está definida por el régimen de poder más reciente por el cual ha sido infundida». (Bingham 2001, 342).

20 Ciertamente, la solución no es, como sugiere Mintz (2004), impartir al estudiante un cuerpo de conocimiento que debe aceptar acríticamente, para que en un momento posterior pueda deshacerse de él y desarrollar un sentido crítico. De la filosofía del espíritu libre de Nietzsche Mintz extrae el siguiente ejemplo educativo: «la desestabilización sólo puede venir después de que el estudiante ha recibido una educación dogmática que ha aceptado acríticamente, ya que debe haber algo firme que el estudiante pueda poner en duda» (Mintz 2004, 165). En nuestra opinión, Mintz se equivoca ante todo al interpretar el pensamiento de Nietzsche. Aunque Nietzsche retrata el espíritu libre como 
afirma que, aunque es necesario que el alumno quiera cuestionarse en primera persona y participar en un proceso de autocrecimiento y transformación, tal proceso de ninguna manera es independiente de lo que uno «escucha, aprende y experimenta de sus maestros» (Cooper 2011, 5). En otras palabras, los profesores tienen la tarea y la responsabilidad de promover y facilitar en cada alumno el logro de una personalidad original y madura.

En mi opinión, para lograr este objetivo es importante adoptar estrategias educativas que promuevan lo que se ha denominado «metacognition». La metacognición se puede definir como la capacidad de analizar críticamente los propios procesos de pensamiento y habilidades cognitivas. Observar el propio progreso ha demostrado ser un elemento muy influyente en la determinación con la que un estudiante se involucra en su propio camino educativo. El estudio de Duckworth \& Eskreis-Winkler (2013) destaca cómo una «mentalidad de crecimiento», («growth mindset») es decir, la creencia de que las habilidades no son innatas sino que se pueden entrenar y mejorar, influye en el camino de aprendizaje. Aprender a evaluar el propio progreso, en mi opinión, puede ser importante no solo para mejorar el aprendizaje del estudiante con respecto a los contenidos curriculares. También y sobre todo, esta metacognición es crucial para que el alumno pueda sentirse parte de su propio camino educativo, aprender a manejar sus propios impulsos y a hacerse cargo de sus propias elecciones.

Respecto al punto 2), en contra de Fennel (2005) argumentamos que, ciertamente Nietzsche está firmemente convencido de que vivir como individuo es una meta que pocos lograrán, ya que solo unos pocos tienen el coraje de

el resultado de un proceso histórico de ruptura contra la tradición, en ninguna parte sugiere que el adoctrinamiento dogmático sea útil ni necesario para luego convertirse en un individuo maduro. Por lo tanto, es absurdo pretender extraer de su filosofía la sugerencia de articular la enseñanza en dos fases: una de adoctrinamiento despótico y la otra de desestabilización. Mintz se apoya en Ramaeker (2001), quien señala que el dogmatismo «es la condición previa para poder ver cualquier cosa, para poder diferenciar entre las cosas» (Ramaeker 2001, 160). En opinión de Nietzsche, el dogmatismo, así como la incapacidad de adoptar una perspectiva (escepticismo de la debilidad) son dos manifestaciones del nihilismo pasivo. Más bien, Nietzsche ensalza el escepticismo de la fuerza, es decir, la capacidad de abrazar y sopesar diferentes perspectivas antes de formar la propia. Este escepticismo requiere una gran capacidad de coordinación interna y caracteriza a los «grandes espíritus», como Zaratustra (AC 64). No es absolutamente necesario recibir adoctrinamiento dogmático para convertirse en uno mismo. Según Nietzsche, cada uno nace y crece en ciertas circunstancias, que en general determinan su perspectiva sobre el mundo, sus valores, que, sin embargo, para convertirse en sí mismo, debe cuestionar. La educación es un proceso en el que se toma conciencia crítica de estas presiones, en el que se distancia de los valores adquiridos inconscientemente y se forma su propia visión.

Mintz (2004) en nuestra opinión malinterpreta los pasajes en los que Nietzsche ataca a las instituciones educativas y expresa desconfianza hacia la posibilidad de su mejora. De este marco no se puede extraer la sugerencia de que primero es necesario crear instituciones muy malas que proporcionen una mala educación, para que luego algunos espíritus fuertes puedan crear su propio camino de autodesucación enfrentándose a estas. 
abrazarlo y apoyarlo hasta el final. Sin embargo, con Jonas $(2008,2021)$ estamos de acuerdo en que, según el Nietzsche de la tercera Intempestiva, el ideal de la autosuperación puede y debe ser propuesto a todos. Como dice Schlegel, formulando una especie de «imperativo categórico del genio»: «Debes exigir que todos sean genio, pero no esperarlo» (citado en Conant 2001, 196). Sin embargo, contra Jonas $(2008,2021)$ debemos observar que Nietzsche no prevé dos objetivos diferentes para dos tipos humanos diferentes. Ya en el momento de la tercera Intempestiva, y aún más explícitamente en Humano, demasiado humano, declara más bien explícitamente que todo el mundo teóricamente tiene la posibilidad de convertirse en un gran hombre. Para Nietzsche, de hecho, la excelencia no se mide por una escala absoluta, sino en relación con el potencial de uno. Para Nietzsche grande es cualquiera que logre ser plena y auténticamente él mismo. Varios individuos excelentes no son comparables entre sí, ya que ese algo en lo que sobresalen es diferente para cada uno. Es por eso que, en nuestra opinión, el ideal de la auto-perfección nietzscheana o la auto-superación pueden y deben ser propuestos hoy a gran escala. Nuestras instituciones y políticas educativas deben promover y fomentar en todos la aspiración a la excelencia, lo que no significa medirse con los otros, sino realizar la mejor versión de uno mismo. ${ }^{21}$

De gran interés es la propuesta de Joosten (2014) de utilizar el concepto de excelencia de Nietzsche para inspirar las políticas educativas contemporáneas. Joosten observa con razón que para Nietzsche sobresalir no significa «ser el mejor», sino «elevarse por encima de uno mismo». Joosten reconoce correctamente cómo, para Nietzsche, la excelencia se mide según una escala individual y no absoluta. Según Joosten, el proceso de «elevarse por encima de uno mismo» consta de tres fases: «autotrascendencia», «autocontrol» y «autoestilismo». En definitiva, se trata de saberse mirar críticamente a uno mismo, a los valores, creencias y hábitos, gestionar mejor las actitudes y pasiones y, si es necesario, tomar una posición a favor o en contra de ellas para desarrollarlas en una nueva dirección. Joosten sostiene que la excelencia, concebida en estos términos «debe formar parte de los programas regulares en la educación superior profesional» (Joosten 2014, 2). De hecho, continúa Joosten, «enseñar a los estudiantes para la excelencia los prepara mejor para una vida profesional que se caracteriza por una complejidad creciente, cambios rápidos y un horizonte de expectativas más corto» (Joosten 2014, 12). La única razón para disentir con respecto a Joosten, - que se centra tanto en el componente de autenticidad como en el de autocontrol - es la motivación que

21 Ver también Simons: «En una atmósfera donde se fomenta el desarrollo de cada uno, no hay razón aparente por la que los que son excepcionales no deban florecer a medida que los más ordinarios también crecen. Las escuelas bien organizadas seguramente deberían ejemplificar esto « (Simons 1988, 348). 
da para desarrollar estas habilidades. Más que simplemente saber adaptarse al mercado laboral, su precariedad y sectorialización, cabe esperar que los nuevos individuos formados por este tipo de educación sean capaces de cambiar este escenario y crear un entorno en el que la dignidad humana y el respeto a las diferencias sean reconocidos como valores supremos.

En conclusión, con respecto a los estudios mencionados anteriormente (Sadler \& Good 2006, Duckworth \& Eskreis-Winkler 2013, y Joosten 2014), sugerimos que, para evaluar realmente la utilidad de adoptar estrategias educativas inspiradas en la filosofía nietzscheana, es necesario asumir como objetivo el mismo que Nietzsche se propuso, es decir, no la inserción del alumno en la lógica del mercado, ni siquiera el aprendizaje de contenidos curriculares, sino su desarrollo como individuo.

\section{REFERENCIAS BIBLIOGRÁFICAS}

ALLEN, A. (2017). «Awaiting education: Friedrich Nietzsche on the future of our educational institutions», en Philosophical Inquiry in Education, 24(3), 197210.

ARCILLA, R. (1995). For the love of perfection: Richard Rorty and liberal education. New York, NY: Routledge.

AVIRAM, A. (1991).« Nietzsche as educator?», en Journal of Philosophy of Education, 25(2), 219-234.

BAIN, K. (2004). What the best college teachers do. Cambridge, MA: Cambridge University Press.

BINGHAM, C. (2001). «What Friedrich Nietzsche cannot stand about education: Toward a pedagogy of self-reformulation», en Educational Theory, 51(3), 337352.

CAVELL, S. (1990). Conditions Hansome and Unhandsome: The Constitution of Emersonian Perfectionism. Chicago/London: University of Chicago Press.

CHURCH, J. (2006). «Dreaming of the true erotic: Nietzsche's Socrates and the reform of modern education», en History of Political Thought, 27(4), 685-710.

CONANT, J. (2001). «Nietzsche's perfectionism: A reading of Schopenauer as educator», en R. Schacht (Ed.), Nietzsche's postmoralism: Essays on Nietzsche's prelude to philosophy's future. Cambridge, UK: Cambridge University Press.

CONWAY, D. (1990). "Nietzsche contra Nietzsche. The Deconstruction of Zarathustra»., en Nietzsche as Postmodernist. Essays pro and contra", ed. C. Koelb, 91-110. New York: SUNY.

COOPER, D. (1983). «On reading Nietzsche on education», en Journal of Philosophy of Education, 17(1), 119-126.

COOPER, D. (2010). Authenticity and learning: Nietzsche's educational philosophy. New York, NY: Routledge.

D'IORIO, Paolo (2012). Le Voyage de Nietzsche à Sorrente: Genèse de la philosophie de l'esprit libre. Paris: CNRS Éditions. ( 
DUCKWORTH, A. L., \& ESKREIS-WINKLER, L. (2013). True grit. Available: http://psychologicalscience.org/observer/true-grit

EWALD, O. (1903). Nietzsches Lehre in ihren Grundbegriffen. Hoffman, Berlin.

GORDON, H. (1980) «Nietzsche's Zarathustra as educator», en The Journal of Philosophy of Education 14(2): 181-192.

HILLESHEIM, J. W. (1986). «Suffering and self-cultivation: The case of Nietzsche», en Educational Theory, 36(2), 171-178.

HILLESHEIM, J. W. (1990). «Nietzschean images of self-overcoming: Response to Rosenow», en Educational Theory, 40(2), 301-306.

HURKA, T. (1992). Perfectionism, en L. Becker (Ed.), Encyclopedia of ethics. New York, NY: Garland Publishing.

HURKA, T. (1993). Perfectionism. Oxford: Oxford University Press.

HURKA, T. (2009). «Nietzsche: Perfectionist», en B. Leiter \& N. Sinhababu (Eds.), Nietzsche and morality. Oxford, UK: Oxford University Press.

JOHNSTON, J. S. (1998). «Nietzsche as educator: A reexamination», en Educational Theory, 48(1), 67-83.

JONAS, M. (2009). «A (R)evaluation of Nietzsche's anti-democratic pedagogy: The overman, perspectivism, and self-overcoming», en Studies in Philosophy and Education 28(2): 153-169.

JONAS, M. (2012). «Gratitude, ressentiment, and citizenship education», en Studies in Philosophy and Education, 31(1), 29-46.

JONAS, M. (2013). «Overcoming ressentiment: Nietzsche's education for an aesthetic aristocracy», en History of Political Thought, 34(4), 669-701.

JONAS, M., and Y. NAKAZAWA (2008). «Finding truth in 'lies': Nietzsche's perspectivism and its relation to education», en Journal of Philosophy of Education, 42(2): 269-285.

JONES, A. (1999). «The limits of cross-cultural dialogue: Pedagogy, desire, and absolution in the classroom», Educational Theory, 49(3), 309.

JOOSTEN, H. (2013). «Learning and teaching in uncertain times: A Nietzschean approach in professional higher education», en Journal of Philosophy of Education, 47(4), 548-563.

JOOSTEN, H. (2014). «Excellence for all: A Nietzschean-inspired approach in professional higher education», en Educational Philosophy and Theory, 47(13/14), 1516-1528.

KATEB, G. (1992). The Inner Ocean: Individualism and Democratic Culture. Ithaca and London: Cornell University Press.

MINTZ, A. I. (2004). «The disciplined schooling of the free spirit: Educational theory in Nietzsche's middle period», en Philosophy of Education, 163-170.

PETERS, M. A., MARSHALL, J. D. \& SMEYERS, P. (Eds., 2001). Nietsche's legacy for education: Past and present values. Westport, CT: Bergin \& Garvey.

RAMAEKERS, S. (2001). «Subjectivism and beyond: on the embeddedness of the Nietzschean individual», en M. Peters e.a (eds.). Nietzsche's legacy for education: past and present values. New York (N.Y.): Bergin and Garvey.

RAWLS, J. (1971). A Theory of Justice. Cambridge, Mass.: The Belknap Press of Harvard University Press. 
ROSENOW, E. (1989). «Nietzsche's educational dynamite», en Educational Theory, 39(4), 307-316.

SADLER, P. M., \& GOOD, E. (2006). «The impact of self- and peer-grading on student learning», en Educational Assessment. 1181): 1-31.

SASSONE, L. A. (2002). The Process of Becoming: A democratic Nietzschean Philosophical Pedagogy for Individualization. Discovery Association Publishing House, Chicago.

SCHACHT, R. (1998). «A Nietzschean education: Zarathustra/Zarathustra as educator», en Philosophers on education, ed. A.O. Rorty, 318-332. London \& New York: Routledge.

SIMONS, M. (1988). «Montessori, Superman, and Catwoman», Educational Theory 38, no. 3, 341-49.

SMEYERS, P. (2001). «Nietzsche and education: Learning to make sense for oneself, or standing for one's ideas», en M. Peters, J. Marshall, \& P. Smeyers (Eds.), Nietzsche's legacy for education: Past and present values. Westport, CT: Bergin \& Garvey.

STEEL, S. (2014). "On the need for Dionysian education in schools today», Educational Theory, 64(2), 123-141.

STOLZ, S. (2017). «Nietzsche on aesthetics, educators and education», en Studies in Philosophy and Education, 36(6), 683-695.

YACEK, D. (2014a).«Going to school with friedrich Nietzsche: The self in service of noble culture», en Studies in Philosophy and Education, 33(4): 391-411.

YACEK, D. (2014b). «Learning to see with different eyes: A Nietzschean challenge to multicultural dialogue», en Educational Theory 64(2): 99-121.

ZAKARAS, A. (2009). Individuality and mass democracy. Oxford: Oxford University Press.

ZAVATTA, B. (2008). «Nietzsche and Emerson on Friendship and Its EthicalPolitical Implications», en H. Siemens and V. Roodt (eds.), Nietzsche, Power and Politics, 511-540. Berlin: De Gruyter.

ZAVATTA, B. (2019). Individuality and Beyond. Nietzsche reads Emerson. New York: Oxford University Press.

ZAVATTA, B. (2022). «Nas raízes do perfeccionismo nietzschiano. Contribuição de Emerson», en Estudos Nietzsche. Edição especial sobre Nietzsche e perfeccionismo. Ed by. Rogerio Lopes. Forthcoming

[Traducción: Luis Enrique de Santiago Guervós

Universidad de Málaga] 